\title{
In-Situ Measurement of Ionospheric E-Region Plasma Irregularities over Taiwan
}

\author{
Chi-Kuang Chao ${ }^{1,2, *}$, Yen-Hsyang $\mathrm{Chu}^{1,3}$, Ching-Lun $\mathrm{Su}^{1}$, and Shigeyuki Minami ${ }^{4}$ \\ ${ }^{I}$ Institute of Space Science, National Central University, Jhongli, Taiwan, ROC \\ ${ }^{2}$ Department of Atmospheric Sciences, National Central University, Jhongli, Taiwan, ROC \\ ${ }^{3}$ Center for Space and Remote Sensing Research, National Central University, Jhongli, Taiwan, ROC \\ ${ }^{4}$ Faculty of Engineering, Osaka City University, Osaka, Japan
}

Received 15 November 2011, accepted 23 December 2011

\begin{abstract}
One ion trap (IT) and one retarding potential analyzer (RPA) onboard the Taiwan Sounding Rocket V (SR-V) were launched to measure ionospheric plasma irregularities on 18 January 2006. After the fairing separated, voltage readings $\left(\mathrm{V}_{\mathrm{G} 1}\right)$ of the first grid (G1) in the IT indicated abnormally high negative voltages appeared at the upleg between 83.7 and $120.1 \mathrm{~km}$ altitude for 19.7 seconds. It is postulated $\mathrm{G} 1$ had temporarily shorted out with the other two grids. Such the anomaly in the $\mathrm{V}_{\mathrm{G} 1}$ brought out the expansion of a plasma sheath around opening of the IT. More ions were attracted into the collector. Remarkable ion currents detected by the IT led to malfunctions of the RPA simultaneously. In this article, laboratory simulations and the International Reference Ionosphere model are performed to evaluate scale factors for the IT to the anomaly. The calibrated total ion concentration profile at the upleg indicates a peak density of the $\mathrm{E}_{\mathrm{s}}$ layer at $93.0 \mathrm{~km}$ altitude of about $6.9 \times 10^{3} \# \mathrm{~cm}^{-3}$ with a thickness of $3.4 \mathrm{~km}$. It is very similar to that at the downleg. It implies that the $\mathrm{SR}-\mathrm{V}$ might encounter the same $\mathrm{E}_{\mathrm{s}}$ layer twice in a distance of $150 \mathrm{~km}$ away.
\end{abstract}

Key words: Ion probe, Sounding rocket, Laboratory simulation, and Plasma chamber

Citation: Chao, C. K., Y. H. Chu, C. L. Su, and S. Minami, 2012: In-situ measurement of ionospheric E-region plasma irregularities over Taiwan. Terr. Atmos. Ocean. Sci., 23, 333-342, doi: 10.3319/TAO.2011.12.23.01(AA)

\section{INTRODUCTION}

Taiwan began a sounding rocket program in 1997. The National Space Organization (NSPO) is responsible for supporting the development of sounding rocket technologies. Local universities provide payloads for scientific research and engineering demonstrations. The Chungshan Institute of Science and Technology (CSIST) provides fabrication and sounding rocket launch services for science missions on demand. In the first phase three sounding rockets (codenamed as SR-I, SR-II, and SR-III) were launched to demonstrate the capacity for academic study before the end of 2003. In the second phase 10 to 15 sounding rockets were planned for launch over the following 15 years. To date, the SR-IV, SR-V, SR-VI, and SR-VII have been launched. The missions include scientific research like neutral wind measurement by releasing trimethylaluminum (Chu et al. 2007)

\footnotetext{
* Corresponding author

E-mail: ckchao@jupiter.ss.ncu.edu.tw
}

from the SR-II and SR-III, ionospheric airglow studies in the SR-IV, plasma irregularities in the SR-V and SR-VII and engineering demonstrations using GPS receivers in the SR-IV, reusable capsules in the SR-VI, and hydrazine propulsion experiments in the SR-VI.

The Ion probe was used primarily to measure the ion temperature and concentrations in laboratory and was then deployed in many early space exploration programs (Boyd 1968). A planar multiple-grid type of ion probe was developed to be installed on many satellite missions, like the Injun 4 and 5, OGO 2, 4, and 6, AEROS A and B, Atmosphere Exlporer C, D, and E, Dynamic Explorer 1 and 2, San Marco-D/L. Special Sensors-Ions, Electrons, and Scintillation installed in the Defense Meteorological Satellite Program series (Heelis and Hanson 1998), Ionospheric Plasma and Electrodynamics Instrument on the first satellite of Republic of China (Yeh et al. 1999), and Ion Velocity Meter on Communication/Navigation Outage Forecasting System (de 
La Beaujardière et al. 2004) were all equipped with the similar ion probes.

Two planar-type ion probes were installed inside the fairing section of the Taiwan's Sounding Rocket V (SR-V) to measure ionospheric E-region plasma irregularities over Taiwan. One of the probes is configured as an ion trap (IT) and the other is a retarding potential analyzer (RPA). Each probe has an $88 \mathrm{~mm}$ diameter opening, three stainless steel T316 woven grids ( 50 meshes per inch and $0.05 \mathrm{~mm}$ diameter wires), and a collector connected to a current meter (see Fig. 1). Each grid is separated at a distance of $4 \mathrm{~mm}$. The distance between the last grid and the collector is $3 \mathrm{~mm}$.

The first grid arranged in the opening of the probe is an aperture grid (G1). Potential of the G1 is electrically isolated with other parts and is supposed to measure a floating potential which varies with the plasma potential under a net current balance. The G1 maintains a uniform electric potential plane to allow plasma coming into the probe smoothly without traversing an electric field. Potential differences $\left(\mathrm{V}_{\mathrm{G} 1}\right)$ between the $\mathrm{G} 1$ of the IT and the rocket ground are recorded. In normal operation, the $\mathrm{V}_{\mathrm{Gl}}$ are close to zero if the G1 is isolated from plasma. If the G1 contacts with the plasma, the $\mathrm{V}_{\mathrm{G} 1}$ go positive (but less than $1 \mathrm{~V}$ in most of the sounding rocket experiments) and increase with plasma density. The second grid arranged behind the G1 is called a retarding grid (G2). In the IT, the potential of the G2 also floats with the plasma potential similar to the $\mathrm{V}_{\mathrm{G} 1}$. However, in the RPA, a feedback circuit provides a $10-\mathrm{Hz}$ square wave, where $\mathrm{V}_{\mathrm{G} 2}$, is also called a retarding voltage, on the $\mathrm{G} 2$ to regulate collector currents of the RPA to levels between 1/5 and $1 / 10$ of the IT (Minami et al. 1982). The $\mathrm{V}_{\mathrm{G} 2}$ of the RPA are recorded and can be used to derive ion temperature by a graphical analysis method in the high sampling rate. The last grid (G3) is a suppressor and biased to $-15 \mathrm{~V}$ to repel all incoming electrons away from the collector. The collector is a $68-\mathrm{mm}$ diameter circular copper plate biased to $-9 \mathrm{~V}$ as its surrounding guarding ring. Currents can be detected when the incoming ions finally hit the collector. The collector currents $\left(\mathrm{I}_{\mathrm{IT}}\right)$ of the IT are recorded and their noise levels are below $0.2 \mathrm{nA}$.

If the $\mathrm{I}_{\mathrm{IT}}$ are too small (less than a threshold level $\sim 0.4 \mathrm{nA}$ ), the feedback circuit of the RPA cannot be triggered and the $\mathrm{V}_{\mathrm{G} 2}$ are always at $-10 \mathrm{~V}$. If the $\mathrm{I}_{\mathrm{IT}}$ are higher than $2 \mathrm{nA}$ (a stable level), the $\mathrm{V}_{\mathrm{G} 2}$ become stable. If the $\mathrm{I}_{\mathrm{IT}}$ fall between the threshold and the stable levels, the $\mathrm{V}_{\mathrm{G} 2}$ are triggered to higher than $-10 \mathrm{~V}$ but fluctuate randomly. It can be realized that both the $1 / 5$ and $1 / 10$ of the $\mathrm{I}_{\mathrm{IT}}$ in stable level are just above the noise level of the current meters. If the $\mathrm{V}_{\mathrm{G} 2}$ are always at $+10 \mathrm{~V}$, it implies that the currents $\left(\mathrm{I}_{\mathrm{RPA}}\right)$ measured by the RPA are lower than the $1 / 10$ of the $\mathrm{I}_{\mathrm{IT}}$. Of course, all the voltages are again referenced to the rocket ground, which is connected to the metal body of the rocket.

In this article, the ion currents collected by the IT of the SR-V are shown first. Extraordinarily high currents are found when the SR-V passes through the $\mathrm{E}$ region at the upleg, but there are no reasonable readings available in the $\mathrm{V}_{\mathrm{G} 2}$ at that time. However, an anomaly in the $\mathrm{V}_{\mathrm{G} 1}$ emerges simultaneously as the extraordinary currents. Laboratory simulations are performed to evaluate possible responses of the IT to the anomaly. The extraordinary currents are mainly caused by a plasma sheath expansion around the IT opening. Scale factors estimated from the laboratory simulations and the International Reference Ionosphere model can be used to restore the E-region total ion concentration profile over Taiwan.

\section{FLIGHT RESULTS OF SOUNDING ROCKET V}

The SR-V was launched at Jioupeng located in the southern part of Taiwan at 19:48:00 National Standard Time

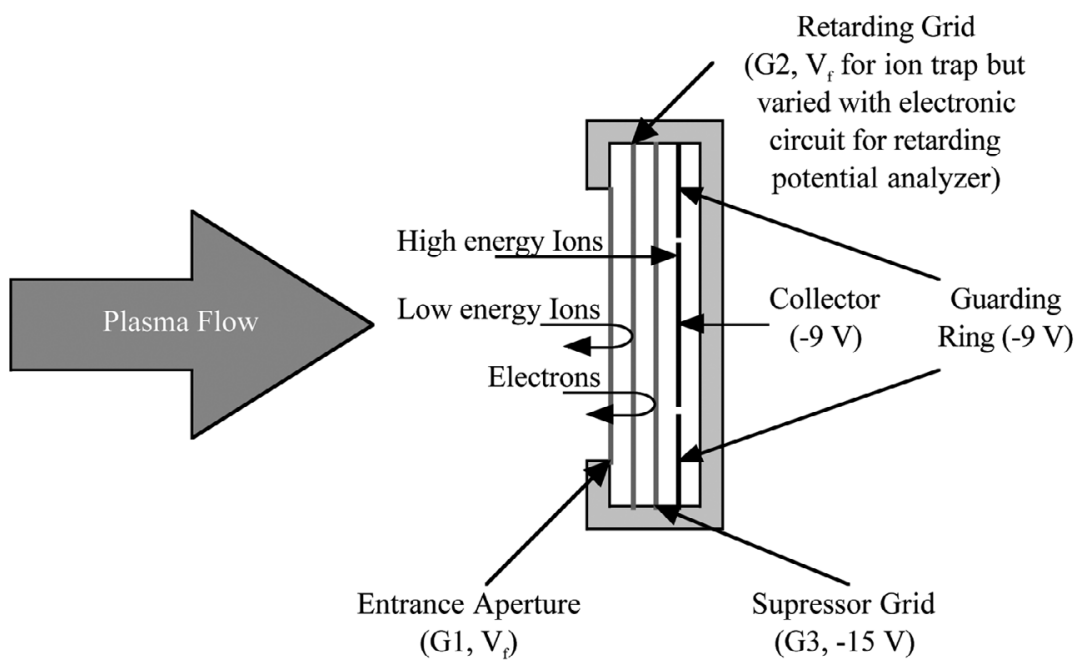

Fig. 1. A cross section illustration of the ion probe onboard the SR-V. 
$(\mathrm{UT}+8)$ on 18 January 2006 . It was directed at an elevation angle of $80^{\circ}$ and at an azimuthal angle $\left(\sim 21^{\circ}\right)$ between Green and Orchid Island. A high spin rate ( $\sim 4 \mathrm{rps})$ was applied to maintain stability of the unguided rocket. Ground radars (a $30 \mathrm{MHz}$ coherent scatter radar and a digisonde) were used to survey ionospheric plasma irregularities near the launch range. However, one of the digisondes close to the launch range failed around 4 hours before the rocket lifted off. The first stage of the rocket was separated at $\mathrm{T}$ $+5.7 \mathrm{~s}(\sim 2.0 \mathrm{~km}$ altitude), where $\mathrm{T}$ is the launch time. The second stage was ignited successfully at $\mathrm{T}+12.1 \mathrm{~s}(\sim 5.0 \mathrm{~km}$ altitude) and then burned out at $\mathrm{T}+43.3 \mathrm{~s}(\sim 49.8 \mathrm{~km}$ altitude). The fairing opened at $\mathrm{T}+58.1 \mathrm{~s}(\sim 79.0 \mathrm{~km}$ altitude) with ground speed $\sim 1.97 \mathrm{~km} \mathrm{~s}^{-1}$ as expected and the ion probes were then exposed outsides to measure ambient plasma. The rocket reached a maximum altitude of $281.1 \mathrm{~km}$ at $\mathrm{T}+270.0 \mathrm{~s}$ in an inertial trajectory but under the effect of aerodynamic drag. An onboard GPS receiver and a 3-axis fluxgate magnetometer recorded its trajectory and attitude information (not a complete solution), respectively, during the flight. The telemetry was terminated at $\mathrm{T}+512.8 \mathrm{~s}$ ( 19.4 km altitude).

Ionospheric ions collected by the IT of the SR-V are represented as ion currents, $\mathrm{I}_{\mathrm{IT}}$, in Fig. 2. At the upleg (see Fig. 2a), a current spike (up to $1.8 \mathrm{nA}$ ) appears around
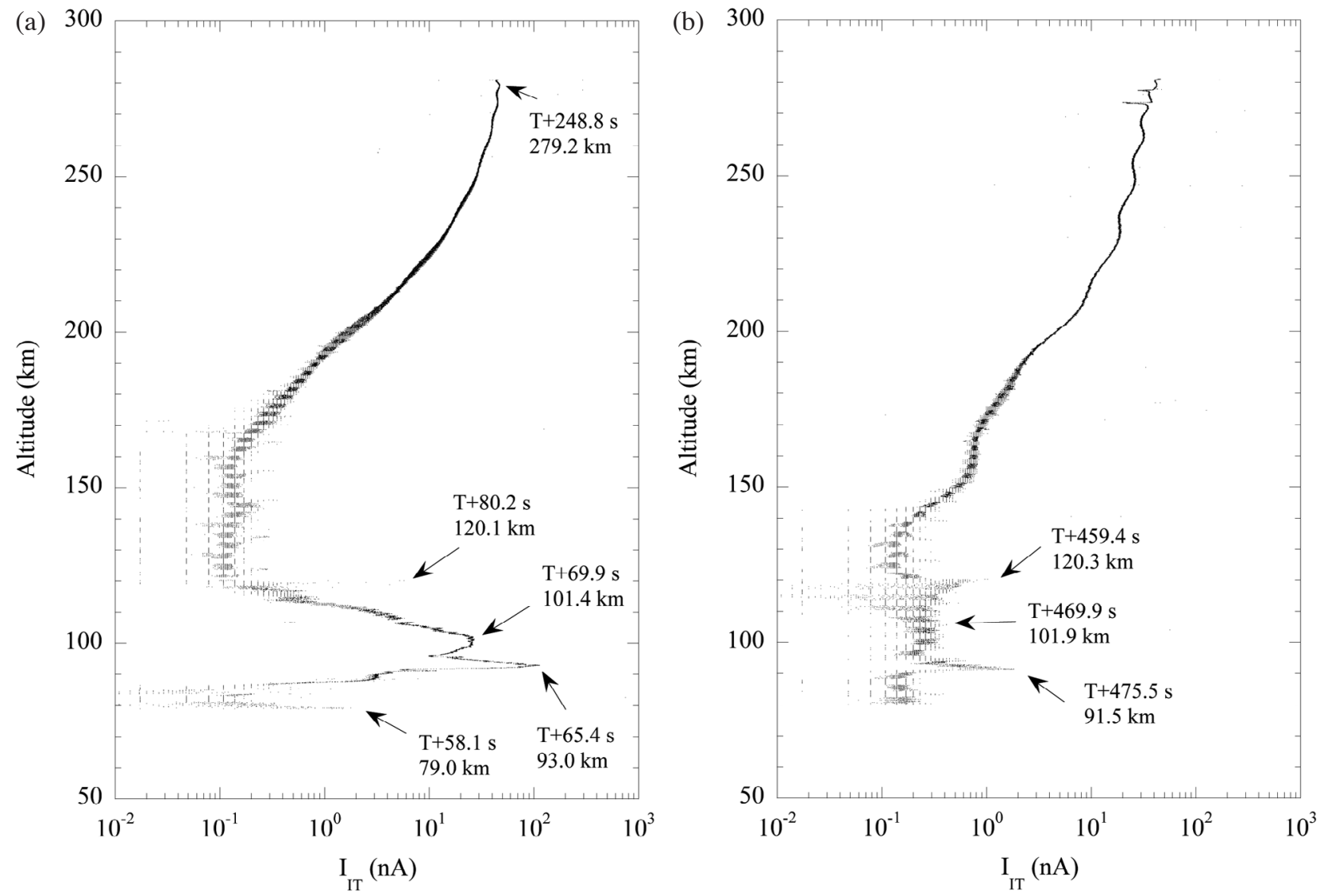

Fig. 2. Ion currents $\left(\mathrm{I}_{\mathrm{TT}}\right)$ measured by the IT onboard the SR-V at the (a) upleg and (b) downleg.
$79.0 \mathrm{~km}$ altitude $(\mathrm{T}+58.1 \mathrm{~s})$. The spike is induced by apparent motion of the grids and the collector within the IT due to a vibration when the fairing opens, not a signal from ambient plasma. It was checked in a random vibration test at ground before the flight. Prominent currents (with level above $1 \mathrm{nA}$ ) are detected with two major peaks between $87.6 \mathrm{~km}(\mathrm{~T}+62.6 \mathrm{~s})$ and $112.3 \mathrm{~km}(\mathrm{~T}+75.8 \mathrm{~s})$ in the $\mathrm{E}$ region. The highest peak $(\sim 113.0 \mathrm{nA})$ is located at $93.0 \mathrm{~km}$ $(\mathrm{T}+65.4 \mathrm{~s})$ with a thickness of $3.4 \mathrm{~km}$. The secondary peak $(\sim 27.1 \mathrm{nA})$ is located at $101.4 \mathrm{~km}(\mathrm{~T}+69.9 \mathrm{~s})$ with a wide coverage of $24.7 \mathrm{~km}$ for the whole region. It seems the highest peak is protruded from the secondary peak. We speculate the highest peak is related to a sporadic-E $\left(\mathrm{E}_{\mathrm{s}}\right)$ layer and the secondary peak is more likely the E peak. These will be discussed in the final section of this article. Meanwhile, a small current spike $(5.8 \mathrm{nA})$ is found at the upleg around $120.1 \mathrm{~km}(\mathrm{~T}+80.2 \mathrm{~s})$ but has a very narrow thickness/duration $(17.5 \mathrm{~m} / 0.01 \mathrm{~s})$. It seems relative to a $\mathrm{V}_{\mathrm{G} 1}$ anomaly that will be described in later paragraphs.

As the SR-V goes up further, only small currents (lower than $1 \mathrm{nA})$ are detected up to $194.0 \mathrm{~km}(\mathrm{~T}+130.3 \mathrm{~s})$. Striplike patterns are shown in the current readings and modulated with altitudes (or time) and current levels. They become remarkable in the low current level due to a switch between two different gains in a pre-amp circuit of the current 
meter every 1-second and a resolution limit of analog-todigital converter in 16 bits for a current sample. Later, in the $\mathrm{F}$ region the $\mathrm{I}_{\mathrm{IT}}$ increase with the altitudes and reach to a maximum $(\sim 47.5 \mathrm{nA})$ at $279.2 \mathrm{~km}(\mathrm{~T}+248.8 \mathrm{~s})$, which is very close to the maximum altitude of the test flight at $281.1 \mathrm{~km}$. Near the maximum altitude, some undulations emerge in the current readings and are caused by coning motion of the rocket. It has been identified by the 3 -axis fluxgate magnetometer installed on the rocket (not shown in this article).

At the downleg (see Fig. 2b), in the F region current undulations have greater perturbations than those at the upleg. On average, the $\mathrm{I}_{\mathrm{TT}}$ are reduced when the rocket falls. Although the gain switch of the pre-amp circuit causes serious contamination in the current readings between 80 and $150 \mathrm{~km}$ altitude where most of the $\mathrm{I}_{\mathrm{IT}}$ are lower than $1 \mathrm{nA}$, some features can be still identified as follows. When the SR-V approaches the E region, a small but significant current spike $(\sim 1.0 \mathrm{nA})$ is detected at $120.3 \mathrm{~km}(\mathrm{~T}+459.4 \mathrm{~s})$ with a thickness of $4.0 \mathrm{~km}$. It is believed that the spike appears when the IT encounters an $\mathrm{E}_{\mathrm{s}}$ layer. However, there is little correlation with the spike close to the similar altitude of the upleg. In a later time, a local current maximum $(0.4 \mathrm{nA})$ is encountered at $101.9 \mathrm{~km}(\mathrm{~T}+469.9 \mathrm{~s})$ and suspected as an E peak, which is very close to the E peak $(101.4 \mathrm{~km})$ at

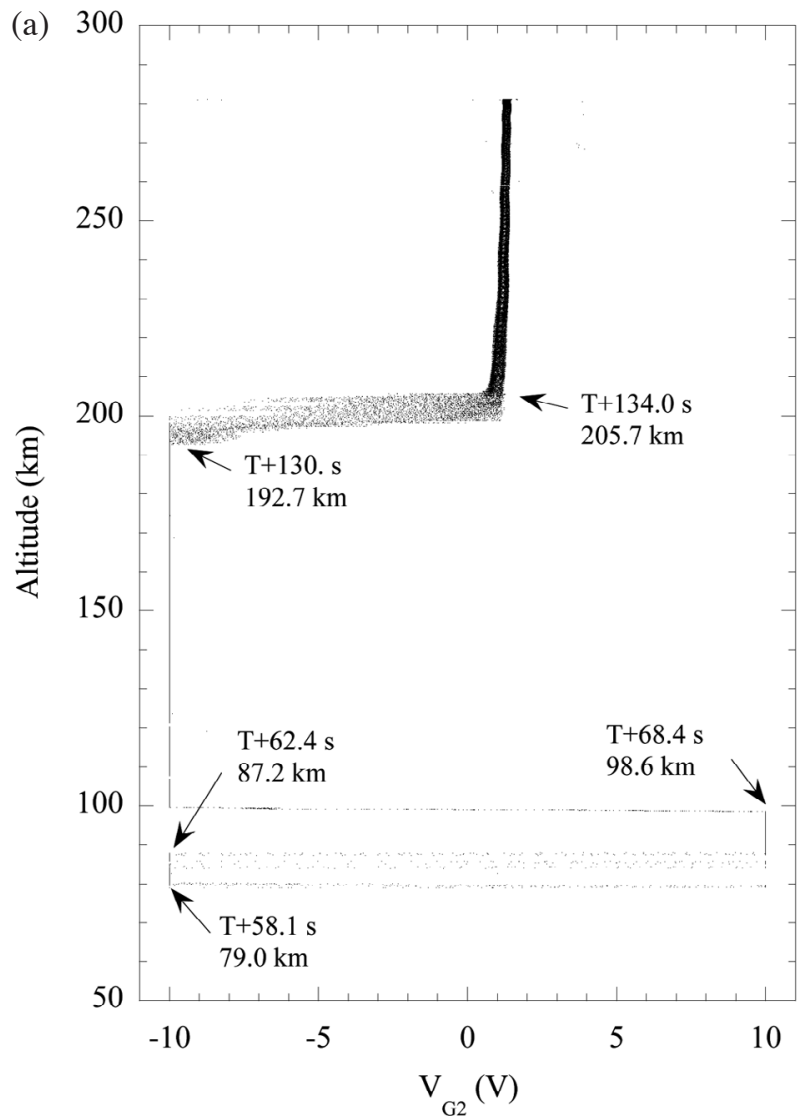

the upleg. Below the E peak, a strong current spike (1.8 nA) emerges at $91.5 \mathrm{~km}(\mathrm{~T}+475.5 \mathrm{~s})$ with a thickness of $4.1 \mathrm{~km}$. It is also classified as an $E_{\mathrm{s}}$ layer and seems to resemble the one at the $93.0 \mathrm{~km}$ of the upleg. In the $\mathrm{E}$ region, the $\mathrm{I}_{\mathrm{IT}}$ at the downleg are overall smaller than those at the upleg.

The $\mathrm{V}_{\mathrm{G} 2}$ readings of the RPA are presented in Fig. 3. At the upleg (Fig. 3a), the $\mathrm{V}_{\mathrm{G} 2}$ are triggered many times before the SR-V approaches the $\mathrm{E}$ region. First the $\mathrm{V}_{\mathrm{G} 2}$ readings are triggered by the vibration-induced $\mathrm{I}_{\mathrm{IT}}(0.48 \mathrm{nA})$ at $\mathrm{T}+58.1 \mathrm{~s}$ $(79.0 \mathrm{~km})$ when the fairing opens and then return back to $-10 \mathrm{~V}$ after the vibration-induced $\mathrm{I}_{\mathrm{IT}}$ are dampened. The $\mathrm{V}_{\mathrm{G} 2}$ are again triggered several times and return to $-10 \mathrm{~V}$ soon, like at $\mathrm{T}+60.6 \mathrm{~s}(83.9 \mathrm{~km})$, at $\mathrm{T}+61.3 \mathrm{~s}(85.2 \mathrm{~km})$, etc. When the SR-V starts to contact the $\mathrm{E}$ region, the $\mathrm{V}_{\mathrm{G} 2}$ readings are triggered by the $\mathrm{I}_{\mathrm{IT}} \sim 0.6 \mathrm{nA}$ at $87.2 \mathrm{~km}(\mathrm{~T}+62.4 \mathrm{~s})$ and become stable at altitudes higher than $87.9 \mathrm{~km}(\mathrm{~T}+$ $62.7 \mathrm{~s}$ ) with the $\mathrm{I}_{\mathrm{IT}} \sim 2.1 \mathrm{nA}$. However, the $\mathrm{V}_{\mathrm{G} 2}$ readings fail to track for both the levels of $1 / 5$ and $1 / 10$ of the $\mathrm{I}_{\mathrm{IT}}$. The $\mathrm{V}_{\mathrm{G} 2}$ stay at $+10 \mathrm{~V}$ until the SR-V reaches $98.6 \mathrm{~km}(\mathrm{~T}+68.4 \mathrm{~s})$. It implies that the $\mathrm{I}_{\mathrm{RPA}}$ readings are always lower than $1 / 10$ of the $\mathrm{I}_{\mathrm{TT}}$ at that moment. However, the $\mathrm{V}_{\mathrm{G} 2}$ gradually return to $-10 \mathrm{~V}$ at $98.6 \mathrm{~km}(\mathrm{~T}+68.4 \mathrm{~s})$ even the $\mathrm{I}_{\mathrm{IT}}$ is as high as the $21.2 \mathrm{nA}$. The reason is unknown and will be left for future study. After the SR-V reaches the $\mathrm{F}$ region, the $\mathrm{V}_{\mathrm{G} 2}$ start triggering but highly fluctuating at $192.7 \mathrm{~km}(\mathrm{~T}+123.0 \mathrm{~s})$

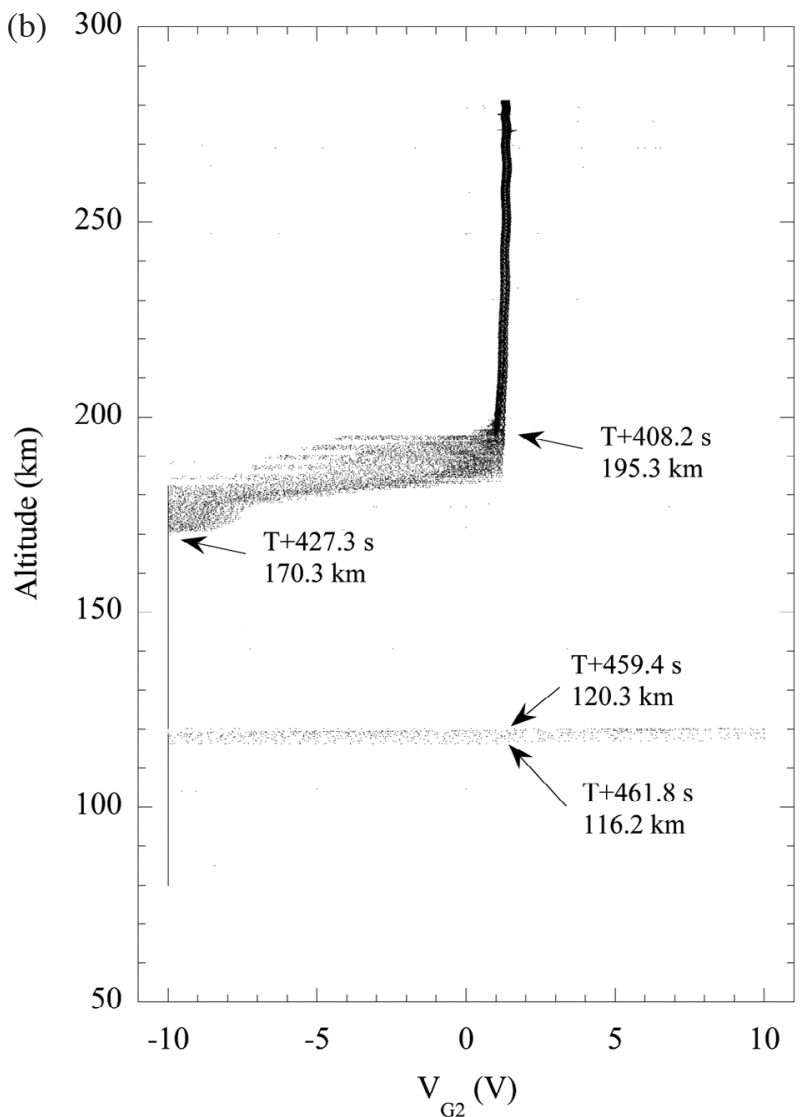

Fig. 3. Retarding voltages $\left(\mathrm{V}_{\mathrm{G} 2}\right)$ measured by the RPA onboard the SR-V at the (a) upleg and (b) downleg. 
where the $\mathrm{I}_{\mathrm{IT}} \sim 1.0 \mathrm{nA}$. The $\mathrm{V}_{\mathrm{G} 2}$ become stable switching between 0.40 and $1.14 \mathrm{~V}$ at the altitudes higher than $205.7 \mathrm{~km}$ $(\mathrm{T}+140.0 \mathrm{~s})$ where the $\mathrm{I}_{\mathrm{IT}}>2.8 \mathrm{nA}$.

At the downleg (see Fig. 3b), the $\mathrm{V}_{\mathrm{G} 2}$ maintain the stable condition until the SR-V falls to $195.3 \mathrm{~km}(\mathrm{~T}+408.2 \mathrm{~s})$ where the $\mathrm{V}_{\mathrm{G} 2}$ switching between 0.46 and $1.29 \mathrm{~V}$ and the $\mathrm{I}_{\mathrm{IT}}$ $\sim 3.1 \mathrm{nA}$. And then the $\mathrm{V}_{\mathrm{G} 2}$ become highly fluctuated toward negative values and cease at $-10 \mathrm{~V}$ at $170.3 \mathrm{~km}(\mathrm{~T}+427.3 \mathrm{~s})$ where the $\mathrm{I}_{\mathrm{TT}}$ have dropped to $0.9 \mathrm{nA}$. When the $\mathrm{SR}-\mathrm{V}$ falls further into the $\mathrm{E}$ region, the $\mathrm{V}_{\mathrm{G} 2}$ are triggered at $120.3 \mathrm{~km}$ $(\mathrm{T}+459.4 \mathrm{~s})$ where the $\mathrm{I}_{\mathrm{IT}} \sim 0.4 \mathrm{nA}$ and cease at $116.2 \mathrm{~km}$ $(\mathrm{T}+461.8 \mathrm{~s})$ where the $\mathrm{I}_{\mathrm{IT}} \sim 0.4 \mathrm{nA}$.

The stable $\mathrm{V}_{\mathrm{G} 2}$ patterns in the $\mathrm{F}$ region can be used to derive the ion temperature in the future. However, no useful $\mathrm{V}_{\mathrm{G} 2}$ readings can be used to determine the ion temperature even though very high $\mathrm{I}_{\mathrm{IT}}(>1 \mathrm{nA})$ readings have been detected in the $\mathrm{E}$ region at the upleg.

Although the $\mathrm{E}_{\mathrm{s}}$ layers are successfully detected during the SR-V flight, an anomaly in the $\mathrm{V}_{\mathrm{G} 1}$ found in the $\mathrm{E}$ region at the upleg (see Fig. 4a) implies more complex situations. From the telemetry, the $\mathrm{V}_{\mathrm{G} 1}$ readings are almost zero when the ion probes are preserved in the fairing. When the fairing opens, the $\mathrm{G} 1$ suffers the vibration to make the $\mathrm{V}_{\mathrm{G} 1}$ jump up to $0.21 \mathrm{~V}$ immediately and then recover to zero in $1.5 \mathrm{~s}$ as the vibration becomes attenuated. At $83.7 \mathrm{~km}(\mathrm{~T}+60.5 \mathrm{~s})$, the $\mathrm{V}_{\mathrm{G} 1}$ readings suddenly but continuously drop from 0 to $-10 \mathrm{~V}$ and maintain at $-10 \mathrm{~V}$ until to $120.1 \mathrm{~km}(\mathrm{~T}+80.2 \mathrm{~s})$. It is noted that the $\mathrm{V}_{\mathrm{G} 1}$ readings are limited within $\pm 10 \mathrm{~V}$, which are the extreme output voltage range of the analogto-digital converter. However, the $\mathrm{V}_{\mathrm{G} 1}$ seems to fall between -10 and $-15 \mathrm{~V}$, which is the lowest voltage provided by a voltage regulator in the ion probes. The $\mathrm{V}_{\mathrm{G} 1}$ become normal after the 19.7-s anomaly and start increasing from 0 to positive values with the altitudes. The $\mathrm{V}_{\mathrm{G} 1}$ go up to $0.40 \mathrm{~V}$ at $279.1 \mathrm{~km}(\mathrm{~T}+248.5 \mathrm{~s})$ very close to the maximum altitude of the test flight.

At the downleg, no anomaly in the $\mathrm{V}_{\mathrm{G} 1}$ is found like the case at the upleg. The $\mathrm{V}_{\mathrm{G} 1}$ remain positive but become small as the SR-V falls. As the SR-V approaches nearby the $\mathrm{E}_{\mathrm{s}}$ layer at $120.3 \mathrm{~km}$, the $\mathrm{V}_{\mathrm{Gl}}$ increase up to $0.19 \mathrm{~V}$ and back to $0 \mathrm{~V}$ after the SR-V passes through it. As the SR-V falls further to the other $\mathrm{E}_{\mathrm{s}}$ layer at $91.5 \mathrm{~km}$, the $\mathrm{V}_{\mathrm{G} 1}$ increase up to $0.01 \mathrm{~V}$ and return to $0 \mathrm{~V}$ soon.

The anomaly in the $\mathrm{V}_{\mathrm{G} 1}$ is speculated as a short circuit between the G1 and the G3 occurring right after the fairing separation. The G2 is probably shortened with the two grids together. The collector remains open to the grids; otherwise a strong negative current should be detected. According to
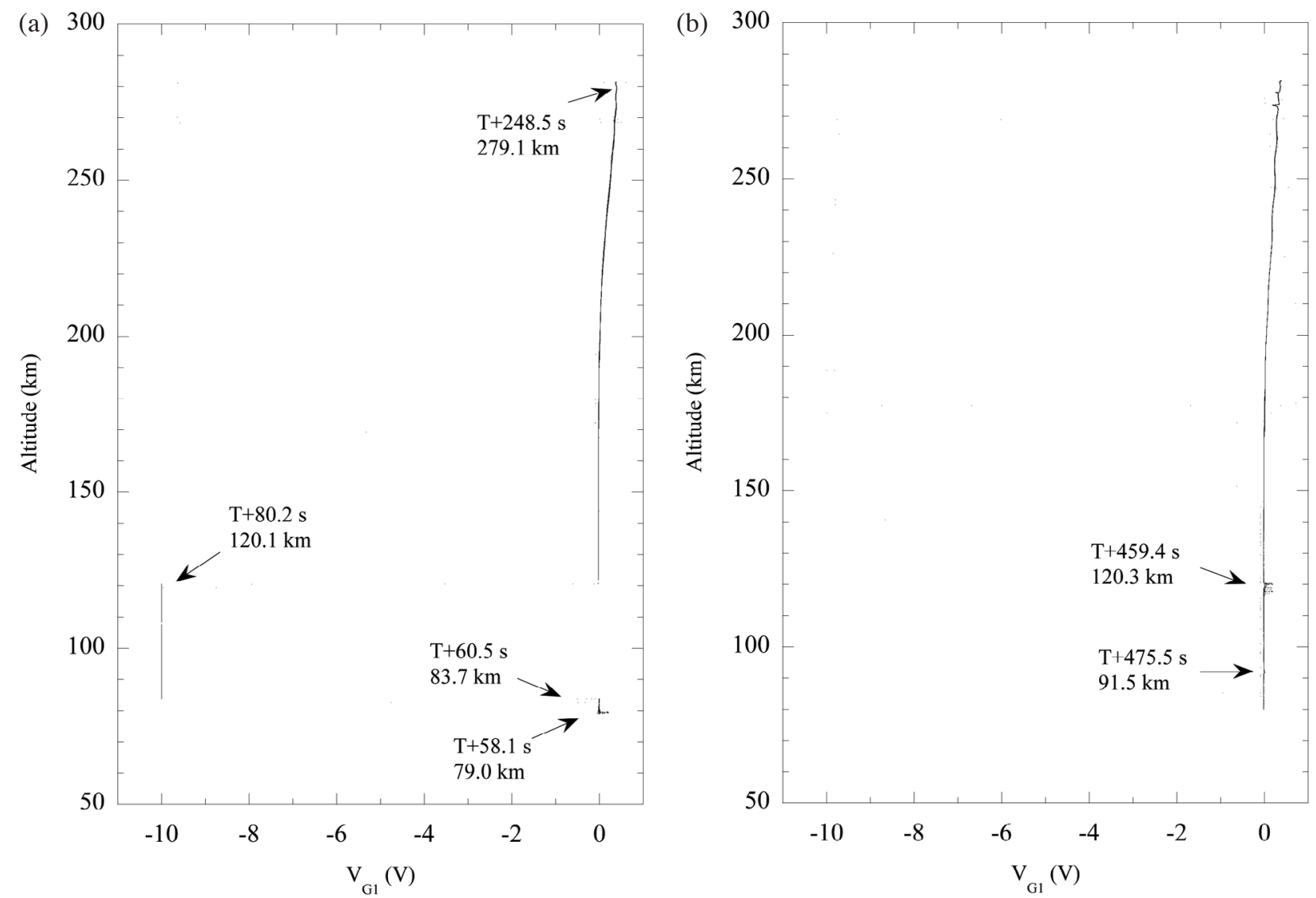

Fig. 4. The $\mathrm{V}_{\mathrm{G} 1}$ variation measured by the IT onboard at the up-leg of the SR-V at the (a) upleg and (b) downleg. One anomaly is shown in the $\mathrm{V}_{\mathrm{G} 1}$ to drop down to $-10 \mathrm{~V}$ at the altitudes between 83.7 and $120.1 \mathrm{~km}$ at the upleg. 
this scenario, the $\mathrm{V}_{\mathrm{G} 1}$ are biased by the $\mathrm{G} 3$ to $-15 \mathrm{~V}$ and the voltage readings become $-10 \mathrm{~V}$ due to the limit of the analog-to-digital converter. One hypothesis for this anomaly is that the metal grids of the IT are deformed by outflowing air. The tension of the metal grids is quite low after inspecting an IT engineering model of the SR-V. The grids contact each other after the fairing opens and then restore to be normal (open circuit) in later time. Before the flight the ion probes are air-sealed in the fairing and purged with dry nitrogen gas continuously at pressure slightly higher than $1 \mathrm{~atm}$ to prevent contamination from water vapor. Another hypothesis is a conductor (especially a metal wire) dropped into the IT after the fairing opens. Pinhole cameras installed in the fairing indicate some tiny objects appear when the fairing opens. The conductor is probably jammed between the $\mathrm{G} 1$ and the $\mathrm{G} 3$ of the IT to let $\mathrm{V}_{\mathrm{G} 1}$ be $-15 \mathrm{~V}$. After the $19.7 \mathrm{~s}$, the conductor may be blown up and the $\mathrm{V}_{\mathrm{G} 1}$ become normal.

The consequence of the anomaly in the $\mathrm{V}_{\mathrm{G} 1}$ results in changes of the $\mathrm{I}_{\text {IT }}$ collection by plasma sheath expansion around the opening of the IT. Abrupt changes in the $\mathrm{I}_{\mathrm{IT}}$ should appear at the $\mathrm{T}+60.5 \mathrm{~s}$ and the $\mathrm{T}+80.2 \mathrm{~s}$, when the $\mathrm{V}_{\mathrm{G} 1}$ drop from 0 to $-15 \mathrm{~V}$ and return from -15 to $0 \mathrm{~V}$, respectively. However, at those moments the current readings are around the noise level of the current meter. No clear current changes are observed to evaluate the effect caused by the anomaly in the $\mathrm{V}_{\mathrm{G} 1}$. Laboratory simulations are required to estimate the $\mathrm{I}_{\mathrm{IT}}$ differences for the $\mathrm{V}_{\mathrm{G} 1}$ at 0 and $-15 \mathrm{~V}$.

\section{LABORATORY SIMULATIONS}

A Space Plasma Simulation Chamber (SPSC) started operation at Space Payload Laboratory, National Central
University in June 2007 to develop and test space payloads in a plasma environment like terrestrial ionosphere. The cylindrical chamber is made of T304 stainless steel to reduce the magnetic field caused by the chamber. The interior space is $700 \mathrm{~mm}$ in diameter and $1500 \mathrm{~mm}$ in length (see Fig. 5a). Two 850-mm doors and twelve 6-in openings $\left(\mathrm{V}_{\mathrm{G} 1} 50\right)$ on the side are used to access and provide feedthroughs to the chamber.

Chamber pressure is monitored by a Pirani vacuum gauge in a low vacuum stage (between 0.4 and $2700 \mathrm{~Pa}$ ) and an ionization gauge in a high vacuum stage (between 1.3 $\times 10^{-5}$ and $0.67 \mathrm{~Pa}$ ). Vacuum pumps are serially connected to one of the chamber openings and evacuated the gases in the chamber to air. A direct-drive oil sealed rotary vacuum pump with a pumping speed at $240 \mathrm{~L} \mathrm{~min}^{-1}$ is used as a foreline/backing pump to reduce the chamber pressure from $1 \mathrm{~atm}$ to $10 \mathrm{~Pa}$. A compound molecular turbo pump with a speed of $750 \mathrm{~L} \mathrm{~s}^{-1}$ is used as a high vacuum pump to reduce the pressure from $300 \mathrm{~Pa}$ to high vacuum. These pumps are manually operated and usually take 8 hours to reduce the chamber pressure from $1 \mathrm{~atm}$ to $10^{-6}$ torr. A clamp valve of automatic leak type is installed in between the rotary pump and turbo pump to prevent inner surface of the chamber from oil contamination once power outage.

A back diffusion plasma source is installed in the door with a 10-inch opening (VG250). The source produces plas-

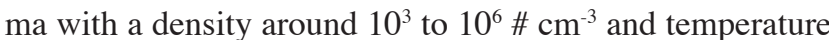
around 1000 to $2000 \mathrm{~K}$ in a thermal ionization process. The plasma source contains replaceable nickel filaments in parallel connection, two acceleration grids, and one back plate as illustrated in Fig. 5b (but not in a real scale). All the grids and the plate are made of T304 stainless steel. Barium carbonate is coated on the filaments and must be activated first. (a)

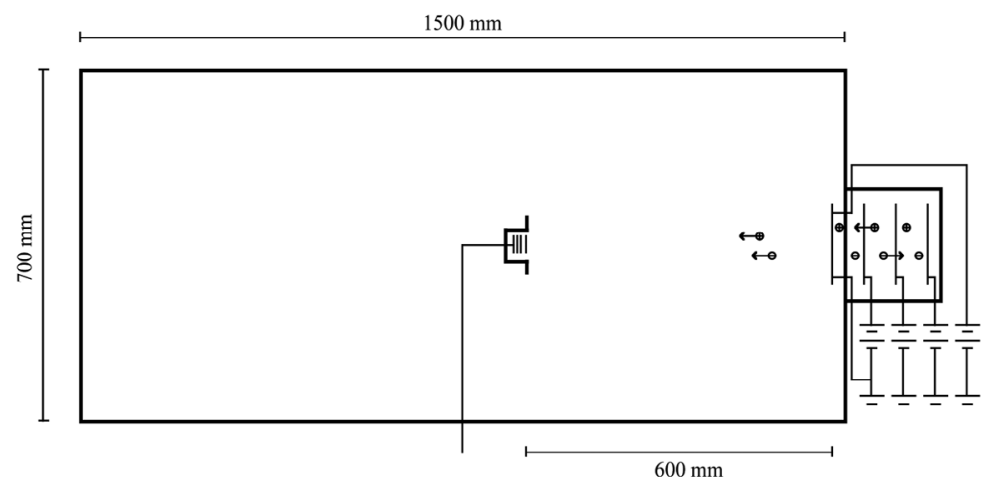

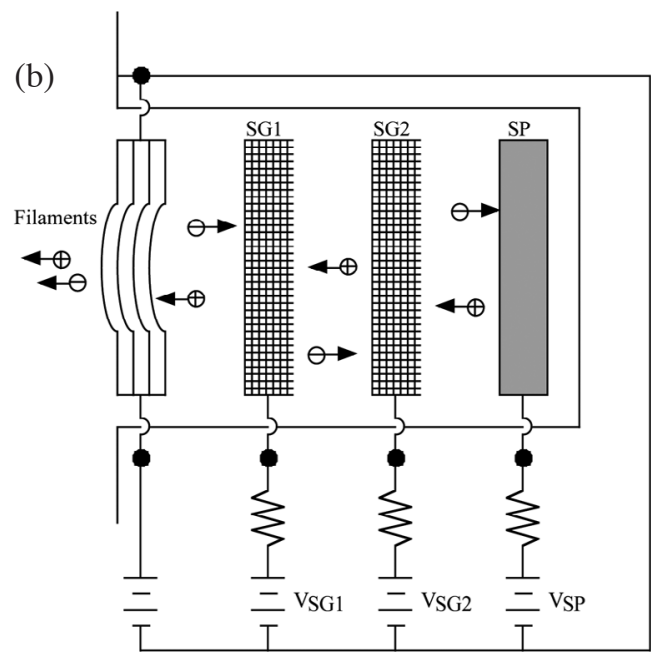

Fig. 5. (a) Schematic of a space plasma simulation chamber and (b) a back diffusion plasma source at the Space Payload Laboratory, National Central University. A back diffusion plasma source is installed in the right-hand side to release plasma toward an IT located at the center of the chamber. The filaments are located at the opening. SG1, SG2, and SP are applied at high positive voltages, $\mathrm{V}_{\mathrm{SG} 1}, \mathrm{~V}_{\mathrm{SG} 2}$, and $\mathrm{V}_{\mathrm{SP}}$, respectively, referenced to chamber body. 
By conducting sufficient electric currents ( $\sim$ several amperes for one filament) through the filaments to red in a slow pace, the coating on the filaments is gradually reacted to release carbon dioxide and become barium oxide. The activated coating has a low work function to allow more electrons escaped from its thermal surface.

The escaped electrons are attracted and accelerated toward inner space of the plasma source by the first acceleration grid (SG1) that is applied to a positive voltage $\left(\mathrm{V}_{\mathrm{SG} 1}\right)$. The electrons are further accelerated toward the back plate by the second acceleration grid (SG2) that is applied to a higher positive voltage $\left(\mathrm{V}_{\mathrm{SG} 2}\right)$. The back plate (SP) is applied to the highest positive voltage $\left(\mathrm{V}_{\mathrm{SP}}\right)$ and also used to stop the electron motions. In the process the electrons collide with released neutral gases and produce new electronion pairs. The produced ions are then accelerated toward the filaments and can carry the electrons out of the source together due to the heavy mass of the ions in an ambipolar diffusion process. The accelerated plasma has a high mean flow in the chamber. The mean velocity can be estimated by the electric potentials $\left(\mathrm{V}_{\mathrm{SG} 1}, \mathrm{~V}_{\mathrm{SG} 2}\right.$, and $\left.\mathrm{V}_{\mathrm{SP}}\right)$ of the grids and plate.

In laboratory simulations, an IT engineering model of the SR-V is installed on a turntable to align the probe opening to normal (as in Fig. 5a) or perpendicular to the plasma source. The G1 and the G2 of the IT are electrically connected to a power supply. The power supply can adjust its output to provide negative voltages on the grids. Collector currents are converted to voltage signals by a pre-amp circuit and recorded by a high-precision 16-bit digital acquisition board. The G3 is maintained at $-15 \mathrm{~V}$ and the collector at $-9 \mathrm{~V}$ as the flight model. All the voltages are grounded to the chamber body and electrical outlets of the laboratory building. Argon gas is released to the chamber at a pressure around $1.08 \times 10^{-2} \mathrm{~Pa}$. The gas release is regulated by a digital mass flow meter/controller with $\pm 1 \%$ accuracy in flow rate. The coating on the filaments is slowly activated to make the plasma flow reach to a stable condition. The biased voltages of the back diffusion plasma source are tuned at $100 \mathrm{~V}$ for $\mathrm{V}_{\mathrm{SG} 1}$, at $130 \mathrm{~V}$ for $\mathrm{V}_{\mathrm{SG} 2}$, and at $200 \mathrm{~V}$ for $\mathrm{V}_{\mathrm{SP}}$. The mean flow speed is estimated $27 \mathrm{~km} \mathrm{~s}^{-1}$ from the voltages of the grids and plate. It is much higher than the ion thermal velocity $\left(0.56 \mathrm{~km} \mathrm{~s}^{-1}\right)$ in the chamber if a typical ion temperature $1500 \mathrm{~K}$ is applied.

In this experiment two extreme cases are performed and their results are shown in Fig. 6. One is to align the opening of the IT to face the plasma source. As the voltages on the $\mathrm{G} 1$ and the $\mathrm{G} 2$ decrease from 0 to $-15 \mathrm{~V}$ in a voltage step of $-2.5 \mathrm{~V}$, the $\mathrm{I}_{\mathrm{TT}}$ (a solid line) received at the collector increase rapidly from $63.3 \mathrm{nA}$ to a saturated level $(\sim 126.0 \mathrm{nA})$ after $-10 \mathrm{~V}$. It is noted that standard deviations of the $\mathrm{I}_{\mathrm{IT}}$ are too small to identify in the figure. The result indicates that the $\mathrm{I}_{\mathrm{IT}}$ for the $\mathrm{V}_{\mathrm{G} 1}$ at $-15 \mathrm{~V}$ is $98.4 \%$ more than that at $0 \mathrm{~V}$. It can be foreseen that negative voltages on the G1 result in plasma sheath expansion around the opening of the IT. Additional ions can fall into the sheath region from side and are attracted into the IT. The result also indicates that the plasma sheath expansion is effective at low negative voltages but limited at high negative voltages.

The other case is to rotate the opening of the IT perpendicular to the plasma source. The variation of the $\mathrm{I}_{\mathrm{IT}}$ (a dashed line) is similar to the previous case but the $\mathrm{I}_{\mathrm{IT}}$ are lower as expected. A very small ion current $(\sim 1.17 \mathrm{nA})$ is collected for the $\mathrm{V}_{\mathrm{G} 1}$ at $0 \mathrm{~V}$. It is because mean plasma flows are unable to go into the IT directly. Only a small fraction of plasma can thermally diffuse into the collector. Once the G1 and G2 are applied to high negative voltages, the plasma sheath expansion allows more ions to slide into the IT. The $\mathrm{I}_{\mathrm{IT}}$ reach to a maximum $(\sim 56.7 \mathrm{nA})$ for the $\mathrm{V}_{\mathrm{G} 1}$ at $-12.5 \mathrm{~V}$. At higher negative voltages the incoming ions caused by the plasma sheath expansion are limited but some of them hitting on the G1 and G2 are lost. The effect can only be analyzed in a simulation model (Chao et al. 2003). The $\mathrm{I}_{\mathrm{IT}}$ for the $\mathrm{V}_{\mathrm{G} 1}$ at $-15 \mathrm{~V}$ is $4580 \%$ more than that at $0 \mathrm{~V}$. It can reinforce the first case that the plasma sheath expansion plays an important role in the current collection.

\section{DISSCUSSION AND SUMMARY}

According to ion temperature and species provided by the IRI-2001 model (Bilitza 2001) under the launch conditions (including time, location, solar flux, magnetic index, etc.), E-region total ion concentration $\left(\mathrm{N}_{\mathrm{i}}\right)$ profiles could be derived from the $\mathrm{I}_{\mathrm{IT}}$. The derivations are based on a onedimensional ion flux equation (Whipple 1959) with consideration of the angle of arrival for the ions into the IT. However, the effects of the coning motion and the spinning of the rocket are not excluded from the data. A small coning

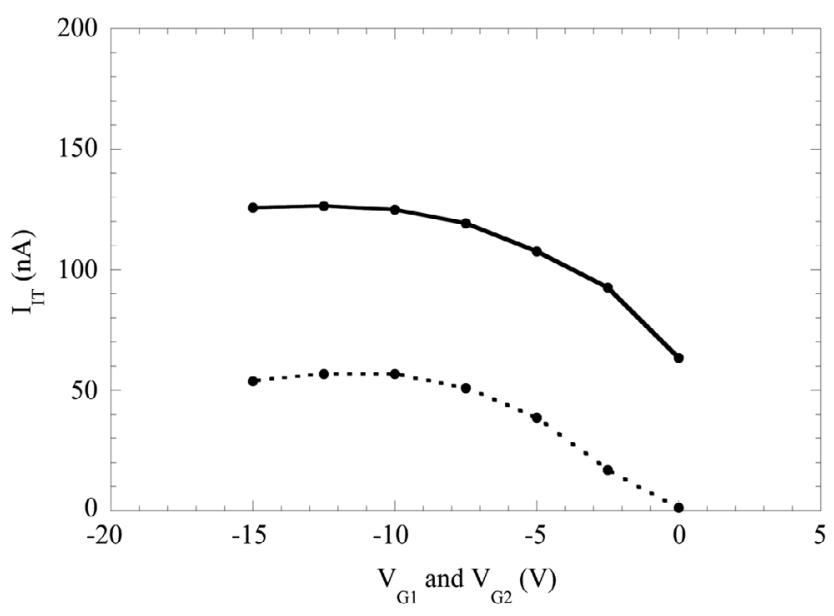

Fig. 6. Ion currents ( $\left.\mathrm{I}_{\mathrm{IT}}\right)$ measured by an engineering model of the ion probe for the SR-V with voltages on G1 and G2 for the probe opening face to (a solid line) and perpendicular (a dash line) to the plasma source. 
motion has been detected by the 3-axis fluxgate magnetometer in the inertial flight of the SR-V. The coning angle of the rocket is less than $10^{\circ}$ and the period around $21 \mathrm{~s}$. It suggested that no dramatic attitude changes when the SR-V passes through the $\mathrm{E}$ region. As for the effect of the spinning, it can be easily identified from those variations around $4 \mathrm{~Hz}$. Hopefully the variations caused by the spinning are small and do not alter the large-scale $\mathrm{N}_{\mathrm{i}}$ profiles much. The calibration processes for these attitude modulations will be investigated in the future work.

Un-calibrated $\mathrm{N}_{\mathrm{i}}$ profiles are represented in black dots in Fig. 7. At the upleg (see Fig. 7a), the $\mathrm{E}_{\mathrm{s}}$ layer at $93.0 \mathrm{~km}$ altitude has an un-calibrated peak density of about $1.9 \times 10^{5}$ $\# \mathrm{~cm}^{-3}$. It should be noted here that the density is over-estimated and will be described in the following paragraphs. At the first glance, it seems common for the $\mathrm{E}_{\mathrm{s}}$ layers observed in many sounding rocket missions. Like the SEEK-1 campaign (Yamamoto et al. 1998), the main $\mathrm{E}_{\mathrm{s}}$ layer has a peak density of around $8.0 \times 10^{4} \mathrm{~cm}^{-3}$ at $98 \mathrm{~km}$ at the upleg and $6.5 \times 10^{4} \mathrm{~cm}^{-3}$ at $100 \mathrm{~km}$ at the downleg. In the SEEK-2 campaign (Wakabayashi et al. 2005), the main $E_{\mathrm{s}}$ layer had a peak density $9.5 \times 10^{4} \mathrm{~cm}^{-3}$ at $104.6 \mathrm{~km}$ at the upleg and $4.7 \times 10^{4} \mathrm{~cm}^{-3}$ at $102.6 \mathrm{~km}$ at the downleg. However, the
$\mathrm{E}_{\mathrm{s}}$ layers detected by the SR-V should have weaker density profiles. It is because the $\mathrm{E}_{\mathrm{s}}$ layers were diminishing during the rocket launch. The $30 \mathrm{MHz}$ radar discovered the plasma irregularities around 18:00 LT and had the strongest echo around 18:30 LT. The echo becomes weaker and ceases at 20:50 LT (not shown in this article).

Meanwhile, the un-calibrated E-peak density is about $4.6 \times 10^{4} \mathrm{\#} \mathrm{cm}^{-3}$, which is much higher than that $(\sim 1.7 \times$

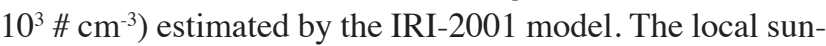
set above the launch range at $100 \mathrm{~km}$ altitude is 18:19 LT. Even though the sunset time at its conjugate point is around 19:27 LT, it is slightly early than the observation time around 19:49 LT. The main ion species, like $\mathrm{NO}^{+}, \mathrm{O}_{2}{ }^{+}$, and $\mathrm{N}_{2}{ }^{+}$, have very high dissociative recombination loss rates in the nighttime E region (Rishbeth and Garriott 1969). The Eregion plasma should diminish in several ten seconds after the sunset. Even the other ionization sources, like starlight and resonantly scattered solar radiation (H Lyman $\alpha$ and $\beta$ ) are considered, the observable electron density has an order of $1 \times 10^{3}$ to $4 \times 10^{3} \mathrm{\#} \mathrm{cm}^{-3}$ in the true nighttime conditions (Strobel et al. 1980; Schunk and Nagy 2009). Therefore, the un-calibrated E-region $\mathrm{N}_{\mathrm{i}}$ profile derived at the upleg is too high to sustain in the nighttime. (a) 130

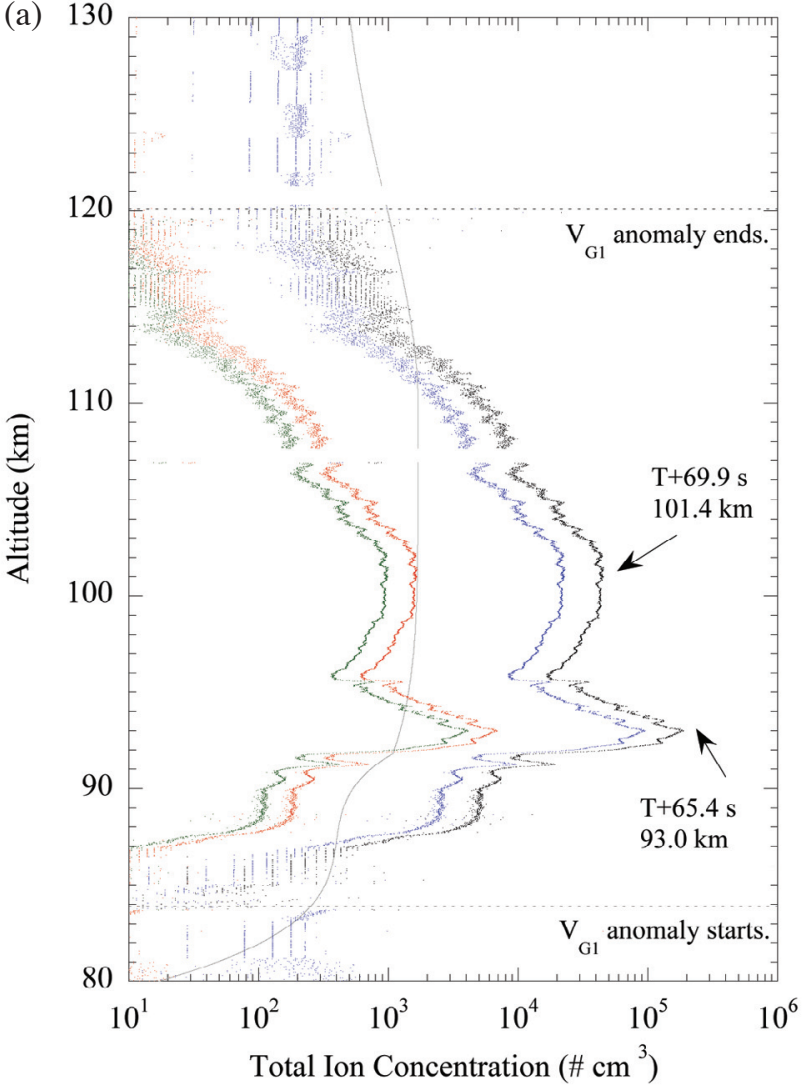

(b)

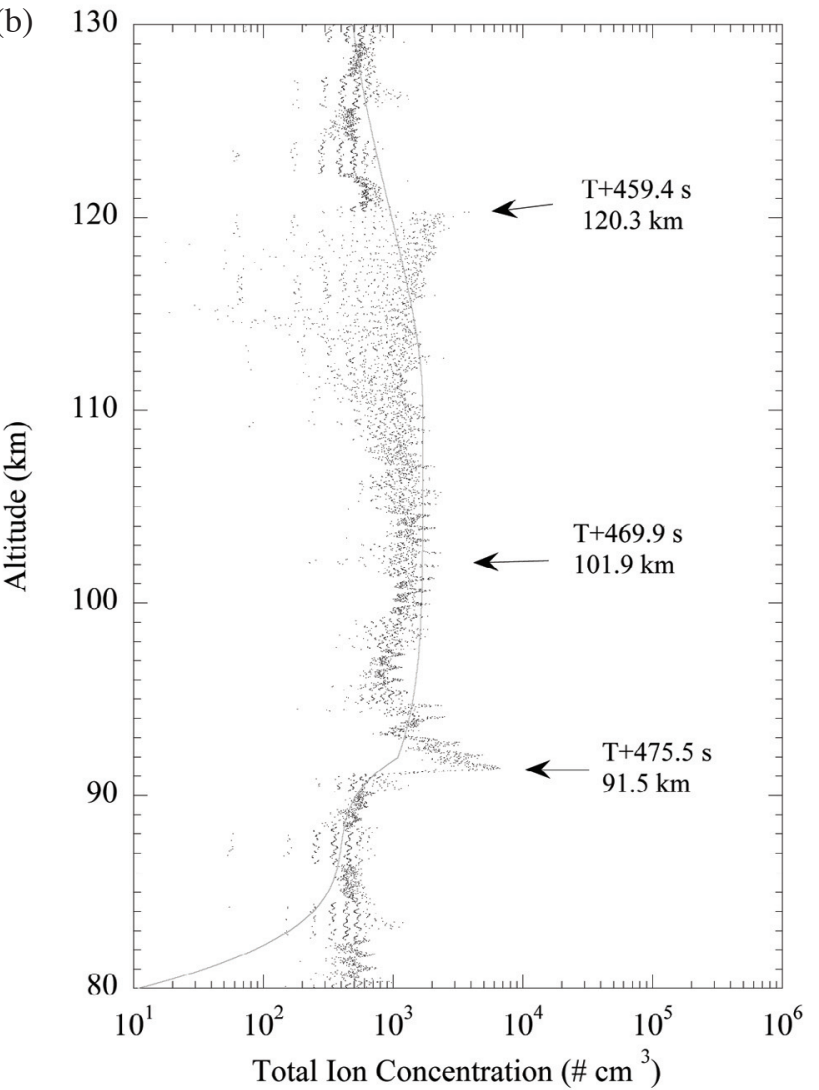

Fig. 7. Total ion concentration $\left(\mathrm{N}_{\mathrm{i}}\right)$ profiles derived from the $\mathrm{I}_{\mathrm{IT}}$ measured by the SR-V at the (a) upleg and (b) downleg. The gray lines indicate the $\mathrm{N}_{\mathrm{i}}$ profiles derived from the IRI-2001 model. The dashed lines indicate the start and end altitude for the $\mathrm{V}_{\mathrm{G} 1}$ anomaly. At the upleg the un-calibrated $\mathrm{N}_{\mathrm{i}}$ profile is plotted in black dots. The calibrated $\mathrm{N}_{\mathrm{i}}$ profiles are plotted in green, blue, and red dots for using scale factors from the lab simulations with the probe perpendicular/face to the plasma source, and from the IRI-2001 model. 
At the downleg (see Fig. 7b), the $\mathrm{N}_{\mathrm{i}}$ derived from the $\mathrm{I}_{\mathrm{IT}}$ match the IRI-2001 model (in gray lines) well near the E peak $(\sim 101.9 \mathrm{~km})$ with an average density of about $1.4 \times$

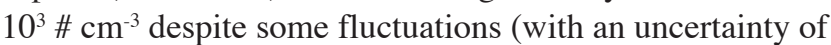

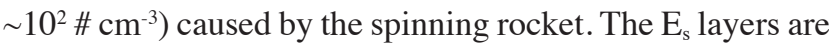
clearly shown at 91.5 and $120.3 \mathrm{~km}$ altitude with density 6.6 $\times 10^{3} \mathrm{\#} \mathrm{cm}^{-3}$ and $3.8 \times 10^{3} \mathrm{\#} \mathrm{cm}^{-3}$, respectively. This information conform our understandings of the $E$ region and $E_{s}$ layer at night and stimulate some methods to calibrate the E-region $\mathrm{N}_{\mathrm{i}}$ profile at the upleg.

The anomaly in the $\mathrm{V}_{\mathrm{G} 1}$ leads to the extraordinarily high $\mathrm{I}_{\mathrm{IT}}$ in the $\mathrm{E}$ region at the upleg. The un-calibrated E-region $\mathrm{N}_{\mathrm{i}}$ profile at the upleg is then over-estimated. It also makes the $I_{I T}$ always higher than the $I_{R P A}$ and no $V_{G 2}$ square wave patterns are available in the $\mathrm{E}$ region like in the $\mathrm{F}$ region.

Although a numerical model has been used to study charged particle motions (Chao and Su 2000) and grid effects (Chao et al. 2003) for an ion probe, it can only be used to evaluate the charged particle scattering by the high negative voltage grids. The effect of the plasma sheath expansion is out of scope of this model. The charged particle scattering for the anomaly in the $\mathrm{V}_{\mathrm{G} 1}$ only accounts $\sim 18 \%$ in additional currents for the SR-V flight condition. The effect is quite smaller than the $98.4 \%$ for the probe faced to the source or $4580 \%$ for the probe perpendicular to the source in the laboratory simulation. The plasma sheath expansion produced by the high negative $\mathrm{V}_{\mathrm{G} 1}$ is probably the main cause to collect extra ions into the IT. The un-calibrated E-region $\mathrm{N}_{\mathrm{i}}$ profile can be scaled down by factors of 1.98 and 46.8 derived from the laboratory simulation to reflect two possible extreme profiles (see Fig. 7b) shown in blue and green dots, respectively. The real solution of the $\mathrm{N}_{i}$ profile may converge within these two profiles. However, the possible profile is most likely the case for the IT facing to the plasma source instead of perpendicular to it from this study. It is because the ground speed $\left(\sim 1.97 \mathrm{~km} \mathrm{~s}^{-1}\right.$ at $100 \mathrm{~km}$ altitude $)$ of the SR-V is much higher than the ion thermal velocity $\left(\sim 0.31 \mathrm{~km} \mathrm{~s}^{-1}\right.$ for $\mathrm{NO}^{+}$with temperature $\left.350 \mathrm{~K}\right)$.

Another way to estimate the scale factor is to use the IRI-model. Since the derived $\mathrm{N}_{\mathrm{i}}$ profile is so similar to the model at the downleg, it suggests that the un-calibrated $\mathrm{N}_{\mathrm{i}}$ profile can be scaled with the $\mathrm{E}$ peak density $\left(1.7 \times 10^{3}\right.$ $\# \mathrm{~cm}^{-3}$ ) from the IRI model. A factor of 27.3 is used to calibrate the $\mathrm{N}_{\mathrm{i}}$ profile (see Fig. $7 \mathrm{~b}$ ) shown by red dots. It is well bound between the two extreme cases from the laboratory simulations. The scale factor is also satisfied in that the $\mathrm{I}_{\mathrm{RPA}}$ are always lower than $1 / 10$ of the $\mathrm{I}_{\mathrm{IT}}$ when the anomaly in the $V_{G 1}$ is encountered. The calibrated $N_{i}$ profile at the upleg indicates the peak density of the $\mathrm{E}_{\mathrm{s}}$ layer at $93.0 \mathrm{~km}$ altitude is about $6.9 \times 10^{3} \mathrm{\#} \mathrm{cm}^{-3}$ with a thickness of $3.4 \mathrm{~km}$. It is very similar to that at $91.5 \mathrm{~km}$ altitude has a density of 6.6 $\times 10^{3} \mathrm{\#} \mathrm{cm}^{-3}$ with a thickness of $4.1 \mathrm{~km}$ at the downleg. It is the best solution for the E-region $\mathrm{N}_{\mathrm{i}}$ profile at the upleg. It implies that the $\mathrm{E}_{\mathrm{s}}$ layer has a wide coverage and the SR-V might encounter the same $E_{s}$ layer twice in a distance of $150 \mathrm{~km}$ away.

Although the probes did not perform flawlessly in the flight test, the anomaly in the $\mathrm{V}_{\mathrm{G} 1}$ gives us some hints to measure a very low plasma density in the present circuit architecture if a careful calibration is applied. The $\mathrm{V}_{\mathrm{G} 1}$ can be applied to a high negative voltage to expand the plasma sheath to collect more plasma into the probe.

Acknowledgements The work has been supported by grant 95-NSPO(B)-SE-FA07-03 National Space Organization, National Applied Research Laboratories and NSC100-2111 -M-008-006 National Science Council of ROC. We also thank members of the Chung-Shan Institute of Science and Technology, Armaments Bureau, Ministry of National Defense for assisting us in launching the Sounding Rocket V.

\section{REFERENCES}

Bilitza, D., 2001: International reference ionosphere 2000. Radio Sci., 36, 261-275, doi: 10.1029/2000RS002432. [Link]

Boyd, F. L. F., 1968: Langmuir probes on spacecraft. In: Lochte-Holtgreven, W. (Ed.), Plasma Diagnostics, North-Holland Publishing Co., Amsterdam, 732-776.

Chao, C. K. and S. Y. Su, 2000: Charged particle motion inside the retarding potential analyzer. Phys. Plasmas, 7, 101-107, doi: 10.1063/1.873817. [Link]

Chao, C. K., S. Y. Su, and H. C. Yeh, 2003: Grid effects on the derived ion temperature and ram velocity from the simulated results of the retarding potential analyzer data. Adv. Space Res., 32, 2361-2366, doi: 10.1016/S0 273-1177(03)90566-7. [Link]

Chu, Y. H., C. L. Su, M. F. Larsen, and C. K. Chao, 2007: First measurements of neutral wind and turbulence in the mesosphere and lower thermosphere over Taiwan with a chemical release experiment. J. Geophys. Res., 112, A02301, doi: 10.1029/2005JA011560. [Link]

de La Beaujardière, O. and the C/NOFS Science Definition Team, 2004: C/NOFS: A mission to forecast scintillations. J. Atmos. Sol.-Terr. Phys., 66, 1573-1591, doi: 10.1016/j.jastp.2004.07.030. [Link]

Heelis, R. A. and W. B. Hanson, 1998: Measurements of thermal ion drift velocity and temperature using planar sensors. In: Pfaff, R. F., J. E. Borovsky, and D. T. Young (Eds.), Measurement Techniques in Space Plasmas: Particles, American Geophysical Union Monograph, 61-71.

Minami, S., S. Tsutsumi, and Y. Takeya, 1982: Graphical analysis method for a retarding potential analyzer and its application to the real-time measurements of ion temperature in space plasmas. Rev. Sci. Instrum., 53, 1709-1713, doi: 10.1063/1.1136874. [Link]

Rishbeth, H. and O. K. Garriott, 1969: Introduction to Iono- 
spheric Physics, Academic Press, New York, 87-125.

Schunk, R. W. and A. F. Nagy, 2009: Ionospheres: Physics, Plasma Physics, and Chemistry, Cambridge University Press, Cambridge, 352-353.

Strobel, D. F., C. B. Opal, and R. R. Meier, 1980: Photoionization rates in the night-time $E$ - and $F$-region ionosphere. Planet. Space Sci., 28, 1027-1033, doi: 10.10 16/0032-0633(80)90050-1. [Link]

Wakabayashi, M., T. Ono, H. Mori, and P. A. Bernhardt, 2005: Electron density and plasma waves in mid-latitude sporadic- $E$ layer observed during the SEEK-2 campaign.Ann.Geophys., 23, 2335-2345, doi: 10.5194/ angeo-23-2335-2005. [Link]
Whipple, E. C., Jr., 1959: Exploration of the upper atmosphere with the help of the third Soviet Sputnik. Proc. IRE, 47, 2023-2024.

Yamamoto, M., T. Ono, H. Oya, R. T. Tsunoda, M. F. Larsen, S. Fukao, and M. Yamamoto, 1998: Structures in sporadic- $E$ observed with an impedance probe during the SEEK campaign: Comparisons with neutral-wind and radar-echo observations. Geophys. Res. Lett., 25, 1781-1784, doi: 10.1029/98GL00709. [Link]

Yeh, H. C., S. Y. Su, Y. C. Yeh, J. M. Wu, R. A. Heelis, and B. J. Holt, 1999: Scientific mission of the IPEI payload onboard ROCSAT-1. Terr. Atmso. Ocean.Sci., 10 (Suppl.), 19-42. 